\title{
What about Data-Driven Business Models? Mapping the Literature and Scoping Future Avenues
}

\author{
Maria Vincenza Ciasullo ${ }^{1}$, Raffaella Montera ${ }^{1} \&$ Emilia Romeo $^{1}$ \\ ${ }^{1}$ University of Salerno, Fisciano, Italy \\ Correspondence: Emilia Romeo, University of Salerno, Fisciano, Italy. E-mail: eromeo@unisa.it
}

Received: March 21, 2021

Accepted: June 7, 2021

Online Published: June 26, 2021

doi:10.5539/ijbm.v16n8p1

URL: https://doi.org/10.5539/ijbm.v16n8p1

\begin{abstract}
The paper aims to perform an assessment of the literature at the intersection of data and business models, examining the extent to which the data-driven business model (DDBM) is considered in the current literature and how it is characterised in terms of approaches, benefits and barriers. A systematic literature review (SRL) of the available body of knowledge on these topics was performed using the Preferred Reporting Items for Systematic Reviews and Meta-Analyses (PRISMA) approach. The SRL reveals limited but rapidly growing coverage of the cutting-edge phenomenon on the part of scientific studies. In problematising the extant literature, competitive, cultural and strategic approaches are proposed together with the relative enablers fostering the adoption of each approach. Benefits and barriers to the implementation of a DDBM are also discussed across technical, organisational and financial dimensions. The insights derived from a critical review of the DDBM literature point out gaps, which may itself inform future research and theory development in this area, as well as support practitioners' decision-making on the datatisation of business models.
\end{abstract}

Keywords: data-drive business model (DDBM), approaches, benefits and barriers, systematic literature review (SRL), research agenda

\section{Introduction}

In recent years, technological changes and the development of digital innovations have disrupted how organisations within different industries do business (Manesh, Pellegrini, Marzi, \& Dabic, 2020). In a similar context, exponential growth in data is affecting firms in the wake of developments in machine learning, big data, cloud and Internet of Things (IoT) technologies. Data can become valuable information that generate new knowledge if they are aggregated, processed and interpreted to extract new value. In this perspective, the value is linked not only to efficiency improvements through the optmisation of internal processes and costs (Manyika et al., 2011; Schüritz \& Satzger, 2016), but also to the opportunity for radical transformations of the business model (BM) (Bocken, Short, Rana \& Evans, 2014) by affecting the achievement of competitive advantage (Opresnik \& Taisch, 2015; Hunke, Seebacher, Schüritz, \& Illi, 2017). This trend of value generation from data has driven the conceptualisation of a data-driven business model (DDBM; Schüritz \& Satzger 2016; Hartmann, Zaki, Feldmann \& Neely, 2016). The DDBM represents a development of the traditional concept of the BM that describes the logic underlying how an organisation creates, delivers and captures value (Osterwalder \& Pigneur, 2010). While traditional BMs consider data as a resource, the DDBM relies on data as the main resource to enhance value creation and appropriation (Engelbrecht, Gerlach, \& Widjaja, 2016; Hartmann, Zaki, Feldmann \& Neely, 2014), despite the fact that a data threshold has not been defined when comparing traditional BMs with data-driven ones (Schüritz, Seebacher \& Dorner, 2017a). In other words, the DDBM's novelty relies on data as a strategic asset (Schrage, 2016) that requires not only an increasingly qualified use of the data but also a cultural change of the corporate mindset. Being a relatively new phenomenon, the DDBM represents an emergent research field (Hartmann et al., 2016; Schüritz et al., 2017; Kühne \& Böhmann, 2019).

While data have gained considerable attention in the information systems (IS) field (Sharma, Mithas \& Kankanhalli, 2014; Abbasi, Sarker \& Chiang, 2016; Baesens, Bapna, Marsden, Vanthienen \& Zhao, 2016; Günther, Mehrizi, Huysman \& Feldberg, 2017), the bridge between data and BMs has rarely been subject to investigation, and its effects remain underestimated. Thus, this topic is still elusive, and best practices have not yet been established (Schmidt, Möhring, Maier, Pietsch \& Härting, 2014; Berger, 2015). On this basis, the paper aims to perform an assessment of the literature at the intersection of data and BMs, responding to recent calls for 
further research on and sustained analysis of DDBMs (Schroeder, 2016; Mikalef, Pappas, Krogstie \& Pavlou, 2020; Wiener, Saunders \& Marabelli, 2020). Therefore, the following research questions are addressed in the paper:

RQ1: To what extent does the DDBM find consideration in the current literature, and how is it characterised?

RQ2: What are the main research directions suggested by the analysis of the literature on DDBMs?

To answer these research questions, a systematic literature review was performed using the Preferred Reporting Items for Systematic Reviews and Meta-Analyses (PRISMA) approach (Moher, Liberati, Tetzlaff, \& Altman, 2009; Mohrer et al., 2015).

Our review contributes to the literature by systematising the scientific knowledge of this cutting-edge phenomenon, problematising key shortcomings, and opening new avenues for investigation into DDBMs; in doing so, the papers findings can also be used to support practitioners' decision-making on the datatisation of BMs.

The paper is structured as follows. Section 2 provides an overview of BMs and digitalisation, while Section 3 describes the methodology used to conduct the systematic literature review. Thereafter, Section 4 reports and discusses the results by identifying the approaches, benefits and barriers to the implementation of DDMBs. Based on these results, a discussion and future research agenda are developed in Section 5. Finally, the theoretical and managerial implications and concluding remarks are reviewed in Section 6.

\section{BM and (Big) Data in the Digitalisation Era: A Theoretical Background}

The academic literature on management provides several BM definitions that partially overlap, since each of them emphasises one or several defining aspects of this multi-dimensional concept (Massa, Tucci \& Afuah, 2017). Specifically, a BM has been defined as a statement (Stewart \& Zhao, 2000), a description (Applegate, 2001), a conceptual tool (Osterwalder \& Pigneur, 2010) and a structural template (Amit \& Zott, 2001). Despite disagreement regarding a unified definition of a BM, there is consensus on at least three points. First, the literature considers the BM as a new unit of analysis distinct from the product, company, industry or network: it is built on the specifications of each firm, but its boundaries are wider than those of the company. Second, it is generally recognised that the BM allows for the means by which firms dynamically do their business to be explained through a holistic approach (Zott, Amil \& Massa, 2011). Third, scholars tend to aggregate the BM components in main dimensions, scholars' coverage of the BM components constitutes an organisation in its entirety, namely the firm's value proposition, market segments, value chain structure, value capture mechanisms, and links between these elements (Saebi, Lien \& Foss, 2017). Thus, a BM is herein understood as the 'architecture for how a firm creates and delivers value to customers and the mechanisms employed to capture a share of that value' (Teece, 2018, p. 40).

Recent developments in the BM literature incorporate the perspectives of data and analytics, thus drawing the conclusion that companies are currently awash in data (Wixom \& Ross, 2017) in both innovative and traditional industries. Accordingly, these developments focus on how to leverage the potentials of digitalisation as a source of competitive advantage. Data have been widely investigated within the IS discipline, with such efforts highlighting their characteristics of volume, variety, velocity and veracity (Baesens et al., 2016; Günther et al., 2017). There have also been studies that have advanced the research that considers data as a multisided socio-economic phenomenon (Abbasi, Sarker \& Chiang, 2016; Wiener, Saunders \& Marabelli, 2020) grounded in the digitalisation era, in which digital technology provides new opportunities for creating value and generating revenue in new competitive contexts (Svahn et al., 2017).

Big data, automation, interconnections along the value chain, and digital customer interfaces have a transformative impact upon an organisation, thereby affecting its BM (Bouwman, de Reuver \& Shahrokh, 2017). This influence implies the optimisation (e.g., cost optimisation), transformation or renovation of the existing BM (e.g., reconfiguration of existing models or the extension of the established business), or development of an entirely new BM (by squeezing out established market participants with new products/services; Chen et al., 2017; Schüritz, Seebacher \& Dorner, 2017). Thus, new horizons are opened for companies in terms of value propositions and access to new resources (Tongur \& Engwall, 2014), value creation and value capture (Velu \& Stiles, 2013), and value delivery to customers through digital infrastructures characterised by the dematerialisation of processes (Warner \& Wäger, 2019). In this regard, existing studies have mainly focused on the changes to the BM components driven by data mostly in isolation, with limited consideration of the implications that changes in one BM component may have on the other ones. In particular, some scholars (i.e., Kiel et al., 2017; Arnold, Kiel \& Voigt, 2020) have pointed out that digitalisation changes the BM in terms of 
new offerings represented by solution packages (i.e., in the form of cloud computing or predictive maintenance) that require the modularisation of hardware and software. Products and services increasingly fuse into highly individualised solutions based on outcomes agreed upon with customers, which paves the way for new segments and markets (Kiel et al., 2017; Müller, 2019). Likewise, new value propositions are expected through improved delivery of existing offerings (i.e., skipping retailers and directly delivering to customers; Burmeister et al., 2016). Thus, value creation needs for flexible activities are characterised by the integration and interoperability of employees, machines, systems and products thanks to real-time access to information along the value chain (Arnold, Kiel \& Voigt, 2020).

The impact of digitalisation on value creation implies new essential digital skills and knowledge around data sourcing, processing and analytics as well as data-based decision-making (Kiel et al., 2017). This requires the traversal of organisational boundaries to continuously integrate new skills and learn new knowledge, thereby complementing the existing capabilities. Thus, more intensified relationships emerge between the partner network and the customer to develop long-term collaborations and trusted interactions (Grandinetti, Ciasullo, Paiola \& Schiavone; Ciasullo, Polese, Montera \& Carrubbo, 2021). Furthermore, digitalisation allows for more efficient operations as well as lower development, transaction and complexity costs (Müller, Buliga \& Voigt, 2018). In addition, digitalisation enables the shift of payments from one-off to continuous cycles in the form of subscriptions and new revenue models (e.g., dynamic pricing or pay-by-usage; Ibarra, Ganzarain \& Igartua, 2018). However, considerations about changing value capture components remain under-represented in the literature.

In sum, the value deriving from data absorbed in BM concerns its use as a key resource (Hartmann et al., 2016), the deployment of data analytics as crucial activities to generate customer value (Wixom \& Schüritz 2017), the presence of data as part of the value proposition (Kühne \& Böhmann 2018) and their monetisation to external parties (Seiberth \& Gründinger, 2018). In any event, the introduction of data and digital technologies within the processes and activities of an organisation has effects depending on the quality of the BM and its degree of resistance to change (Chesbrough, 2010).

\section{Method}

A systematic literature review (SLR) was carried out between June and August 2020 to synthesise empirical evidence from previous studies, provide an overview of the current body of knowledge on DDBMs and describe directions for future research (Linares-Espinós et al., 2018). More specifically, according to our research purposes, the investigation focused on the following review questions based on the above-mentioned research questions:

- What are the main approaches to developing DDBMs and the relative enablers fostering the adoption of each approach?

- What are the main benefits and barriers to the implementation of a DDBM?

The SLR was conducted using PRISMA as a systematic and rigorous procedure to search, filter, select and analyse the findings from the literature based on the objective of the study (Moher et al., 2009; 2015). PRISMA was chosen because it ensures a thorough planning of the review from the start to the end, guaranteeing the methodological accuracy, replicability and transparency of research (Tranfield, Denyer \& Smart, 2003). To perform the SLR, PRISMA's steps, which include identification, screening, eligibility and inclusion (Moher et al., 2009), were performed as described below and in Figure 1.

\subsection{Identification}

The review questions guided the identification of keywords as search strings to isolate the relevant literature from Scopus and the Web of Science Core Collection (WOS) databases, which were chosen for their extensiveness and relevance in the social sciences (Norris \& Oppenheim, 2007). The keywords were connected with the 'AND' and 'OR' Boolean operators. Thus, the following search strings were defined: "data-driven" OR "big data" OR "data analytics" AND "business model"; "data-driven" OR "big data" OR "data analytics" AND "business model" AND "innovation"; "digitali*ation" AND "business model". These sets of keywords needed to be contained in the title, abstract or keywords to ensure a comprehensive search. In doing so, 397 records were produced (310 from Scopus and 87 from WOS).

\subsection{Screening and Eligibility}

A total of 146 of the 397 records from Scopus and WOS resulted in duplicates and were thereby rejected. In line with Cooper's methodology (1998), inclusion and exclusion criteria were set to obtain the relevant literature in the databases. Book chapters, editorials and working papers were excluded, while articles published in 
international peer-reviewed journals and conference proceedings were included in the analysis. Moreover, only documents written in English and belonging to the specific research fields of business management and social sciences were considered. On this basis, 231 records were screened. Of these 231 records, titles and abstracts were read to identify those most appropriate to the research area and review questions. Thus, 168 results were removed, and 63 articles were assessed for eligibility.

\subsection{Inclusion}

After reading the full texts of the 63 remaining articles, 45 publications were included in the review process because they contributed to answering the review questions (Appendix A), as explained below. Moreover, the number of papers included is considered to be acceptable according to Robinson and Lowe (2015), who recommended the inclusion of 10-50 papers for SRL.

The final set of 45 works was analysed both descriptively and thematically. The descriptive analysis was deductive in nature and aimed to classify the studies in terms of publication type, journal, temporal and geographic distribution, methodological approach and industries investigated. In the thematic analysis, an inductive approach was adopted (Bales, Krippendorff \& Bock, 2009), and three researchers independently coded and grouped the studies. Next, they discussed these determinations by phone, on Skype or in face-to-face meetings to safeguard the quality of the review. Thus, the thematic analysis of the selected works concerned the following three themes: i) approaches to DDBMs; ii) benefits of DDBMs; and iii) barriers to DDBMs.

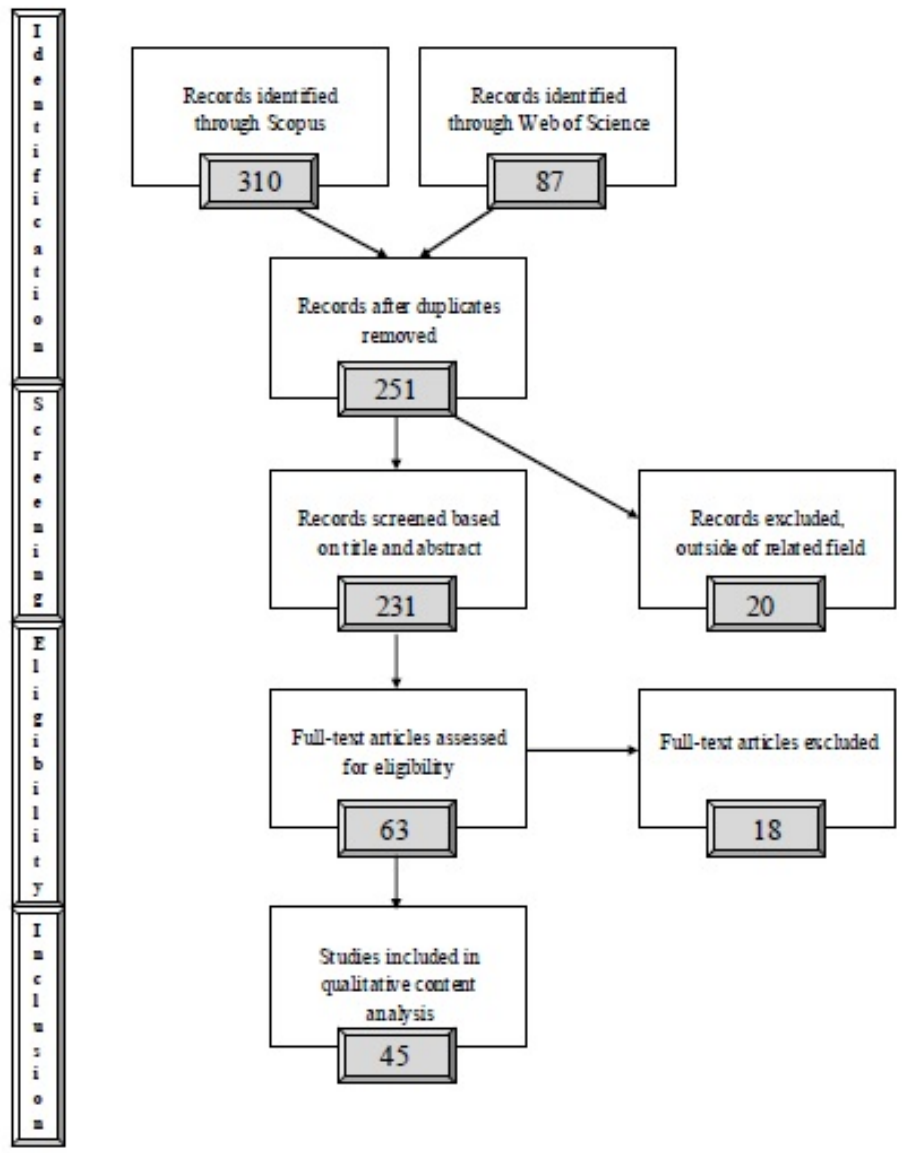

Figure 1. PRISMA flow diagram 


\section{Findings}

\subsection{Descriptive Analysis}

Figure 2 depicts the scarcity of studies on DDBMs due to the emerging nature of this research field. Of note, the small number of peer-reviewed articles compared to the conference proceedings reveals an ongoing managerial debate within the scientific community.

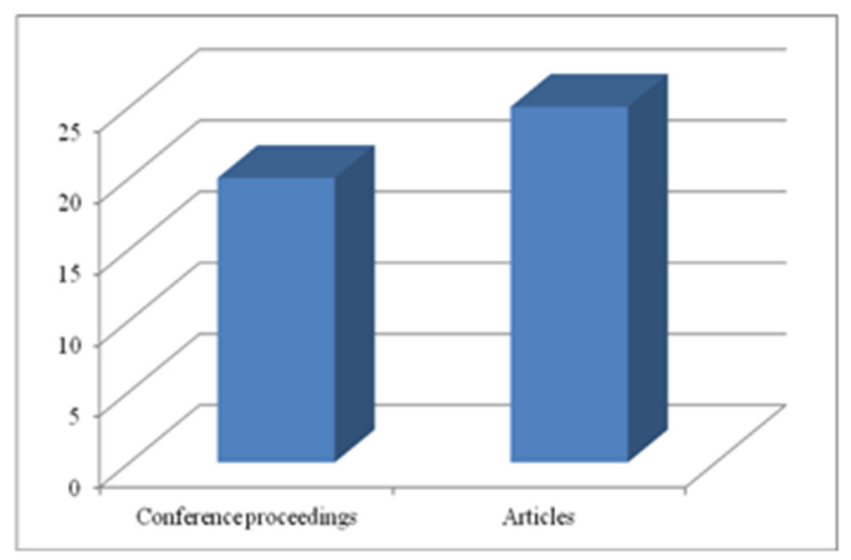

Figure 2. Publication type

In capturing how the literature set was spread across different journals, Table 1 shows the prevalence of journals focused on product and service management, thus confirming the strategic implications of DDBM implementation. Focusing on the journal impact factor (IF) retrieved from the Journal of Citation Reports (JCR), DDBMs were found to be addressed by the high-profile scientific community, which highlights the importance of this emergent topic.

Table 1. Articles per journal

\begin{tabular}{llc}
\hline Journal & IF & Frequency \\
\hline Technovation & 6.28 & 1 \\
Journal of Product Innovation Management & 5.00 & 1 \\
Industrial Marketing Management & 4.69 & 1 \\
International Journal of Operations and Production Management & 4.61 & 1 \\
Business Horizons & 4.49 & 1 \\
Journal of Service Management & 3.75 & 1 \\
IEEE Access & 3.74 & 1 \\
Journal of Service Marketing & 3.19 & 1 \\
Review of Managerial Science & 3.00 & 1 \\
European Journal of Innovation Management & 2.61 & 1 \\
Neural Computing and Applications & 2.50 & 1 \\
Telecommunication Policy & 2.22 & 1 \\
Computer Law \& Security Review & 1.84 & 1 \\
Journal of Business Strategy & 1.19 & 1 \\
International Journal on Advanced Science, Engineering and Information Technology & 1.18 \\
Research in the Sociology of Organization & 0.97 & 1 \\
National Institute Economic Review & 0.89 \\
International Journal of Social Ecology and Sustainable Development & 0.35 & 1 \\
Advanced in Transdisciplinary Engineering & 0.32 & 1 \\
Journal of Chinese Economic and Foreign Trade Studies & 0.27 \\
Iranian Journal of Information Processing and Management & 0.21 \\
Applied Marketing Analytics & 0.12 & 1 \\
\hline
\end{tabular}

Note. Table 1 does not include Big Data and Cognitive Computing, Technology Innovation Management Review, and Journal of Management Science and Engineering, whose IF is not reported in the JCR. 
In addition, a higher number of contributions came from published conference proceedings conferences in the Information Systems and Engineering domain (Table 2).

Table 2. Articles per conference

\begin{tabular}{lc}
\hline Conference & Frequency \\
\hline Conference on Business Informatics & 4 \\
Conference on Information Systems & 2 \\
International Conference on Engineering, Technology and Innovation & 2 \\
Americas Conference on Information Systems & 2 \\
International Conference on Innovation \& Management & 1 \\
European Conference on Information Systems & 1 \\
International Conference on Knowledge-Based and Intelligent Information \& Engineering Systems & 1 \\
International Conference on Engineering Design & 1 \\
Australasian Conference on Information Systems & 1 \\
Tagungsband Multikonferenz Wirtschaftsinformatik & 1 \\
International Enterprise Distributed Object Computing Workshop & 1 \\
Bled eConference & 1 \\
Procedia CIRP & 1 \\
International Conference on Business Information Systems & 1 \\
\hline
\end{tabular}

In terms of citations (Table 3), Hartmann et al. (2016) are the most cited authors, having proposed the first empirically derived taxonomy of DDBMs in start-ups by identifying six DDBM types and providing a systematic overview of the different ways to create DDBMs. They are followed by Sorescu (2017), who highlights that external and internal data form the foundation of BM innovation.

Table 3. Citations

\begin{tabular}{|c|c|c|}
\hline Authors & Article & No. of citations \\
\hline Hartmann et al. (2016) & $\begin{array}{l}\text { Capturing value from big data - A taxonomy of data-driven business models used by } \\
\text { start-up firms }\end{array}$ & 264 \\
\hline Sorescu (2017) & Data-driven business model innovation & 103 \\
\hline Immonen et al. (2014) & Requirements of an open data-based business ecosystem & 76 \\
\hline Urbinati et al. (2019) & $\begin{array}{l}\text { Creating and capturing value from Big Data: A multiple-case study analysis of } \\
\text { provider companies. }\end{array}$ & 59 \\
\hline Schüritz \& Satzger (2016) & Patterns of data-infused business model innovation & 54 \\
\hline Zolnowski et al. (2016) & Business model transformation patterns of data-driven innovations & 48 \\
\hline Trabucchi \& Buganza (2019) & Data-driven innovation: switching the perspective on Big Data & 43 \\
\hline Cheah \& Wang (2017) & $\begin{array}{l}\text { Big data-driven business model innovation by traditional industries in the Chinese } \\
\text { economy }\end{array}$ & 40 \\
\hline Krämer \& Wohlfarth (2018) & Market power, regulatory convergence, and the role of data in digital markets & 38 \\
\hline Zaki (2019) & $\begin{array}{l}\text { Digital transformation: harnessing digital technologies for the next generation of } \\
\text { services }\end{array}$ & 36 \\
\hline
\end{tabular}

In terms of temporal and geographic distribution, the works analysed were published between 2014 and 2020, with a peak in 2017 (Figure 3). In addition, Germany was found to be the country most involved in research on DDBMs (Figure 4). 


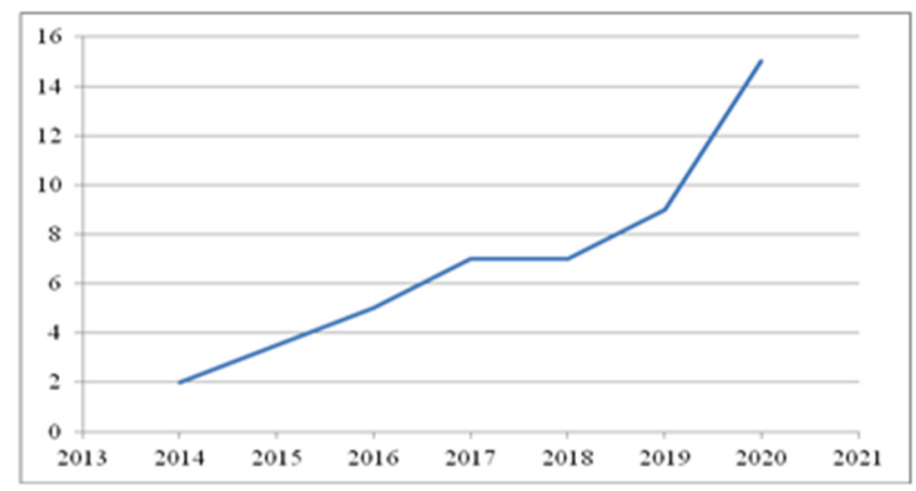

Figure 3. Articles published per year

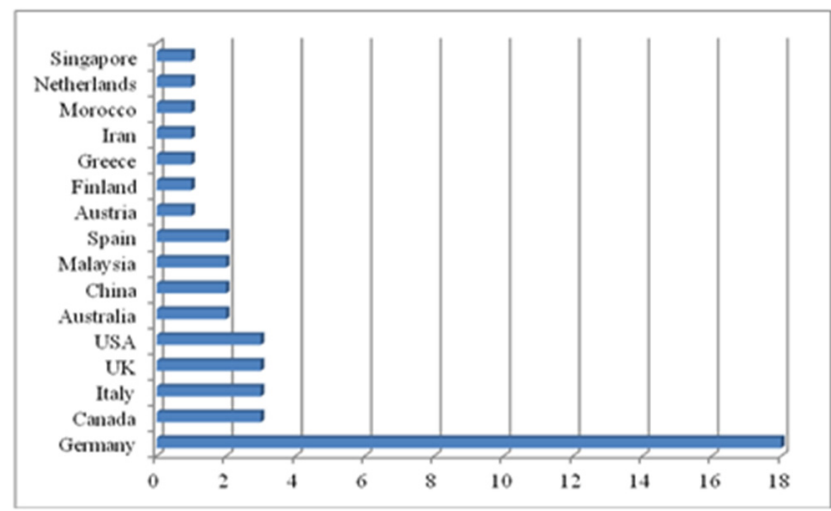

Figure 4. Articles per country

Regarding the methods (Table 4), most of the research took a theoretical approach, with literature reviews dominating the sample, thus confirming the infancy of this research field.

Table 4. Methods

\begin{tabular}{llc}
\hline Paper type & Method & No. of works \\
\hline Theoretical & Literature review & 15 \\
& Concept development & 7 \\
& Content Analysis & 5 \\
& Total & 27 \\
Empirical & Qualitative & 14 \\
& Quantitative & 4 \\
& Total & 18 \\
\hline
\end{tabular}

Empirical studies were mainly conducted in miscellaneous sectors (Sorescu, 2017; Hunke et al., 2017; Kühne \& Böhmann, 2018). In addition, services were an industry frequently investigated (Zaki, 2019; Breidbach \& Maglio, 2020). Moreover, research on DDBMs seems not to be limited to the computer and IT industries. In fact, some studies show that companies operating in the traditional manufacturing industries harness the power of big data to transform the way they conduct their businesses (Cheah \& Wang, 2017; Schaefer, Walker \& Flynn, 2017; He, Xue $\& \mathrm{Gu}, 2020)$. 


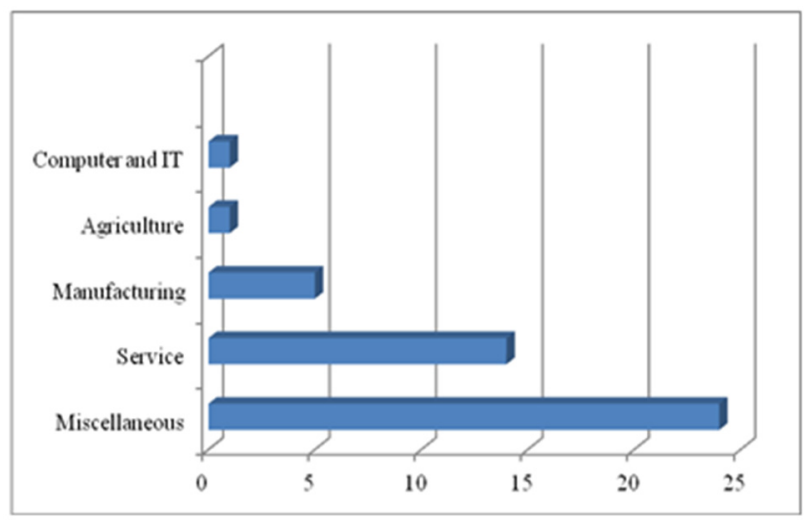

Figure 5. Industries

\subsection{Thematic Analysis}

\subsubsection{Approaches to DDBMs}

Thematic analysis allows for the classification of three approaches to DDBMs and also identifies the relative lever that fosters the adoption of each approach (Table 5).

First, a competitive approach emerged in $46 \%$ of the articles selected, in which data were recognised as core resources of value creation in the digital era (Tsvetkov \& Chekanov, 2019). Their increased availability, combined with data processing techniques and big data analytics capabilities, was shown to increase operational efficiency, enhance organisational performance, assist managers' decision-making, transform BMs and create new ones (Yoo, Lyytinen, Boland, \& Berente, 2010; Westerman \& Bonnet, 2015; Chaudhary, Pandey \& Pandey, 2016; Sadowski, 2019). In sum, data act as strategic assets for generating knowledge to improve competitiveness while also providing benefits for the whole value chain (Chen, Mao, Zhang \& Leung, 2014; Gupta \& George, 2016). Drawing on the seven studies selected (Table 5), top management support represents a lever fostering the adoption of a competitive approach. In particular, managers should ensure that the organisational infrastructure and human resources are well suited for extracting value from a massive influx of big data coming through multiple sources. Thus, a supportive attitude on the part of management can empower the development of a conducive environment for exploring data and generating actionable insights in terms of BM innovation and competitive advantage (Cheah \& Wang, 2017).

Second, a cultural approach emerged in $32 \%$ of the articles selected, in which the importance of a mindset based on widely available and accessible data was recognised as a basis for value propositions and decision-making processes (Babar \& Yu, 2019). By going beyond both intuition and experience (LaValle, Lesser, Shockley, Hopkins \& Kruschwitz, 2011; Brynjolfsson, Hitt \& Kim, 2011), data become a driving force to inform actions, predict complexity and foster change (Polese, Botti, Grimaldi, Monda \& Vesci, 2018). By drawing on the four studies selected (Table 5), those factors facilitating the adoption of a cultural approach are data literacy and quality. On the one hand, data literacy embraces a specific skill set and knowledge basis that enables one to understand the meaning of data, draw correct conclusions from them and recognise their misleading or inappropriate usages (Mandinach, Honey, Light \& Brunner, 2008; Carlson, Fosmire, Miller \& Nelson, 2011). On the other hand, data quality ensures the extraction of reliable information that can be used for tactical and strategic aims, contributing to the optimisation of processes, improvement of offerings and increases in turnover (Kwon, Lee \& Shin, 2014).

Third, a strategic approach was employed in $22 \%$ of the articles selected, in which the strategic management of data was shown to be a priority for BMs based on data. The DDBM implementation implies not only a strong infrastructure based on technological tools, platforms and solutions, but also effective data governance. The latter requires the definition of policies, roles, processes and responsibilities communicated to all organisational levels to fully control the alignment between data and corporate objectives, leading to the identification of the specific benefits provided by data in its own context (Heudecker \& Kart, 2014; Schmidt et al., 2014). By drawing on the two studies selected (Table 5), the adoption of a strategic approach is facilitated by the design of a data-driven environment, in which it is known which data to focus, how to allocate analytic resources, how to deploy and use data, how to measure the impact of the data-driven initiatives or how to address issues of data security. 
Table 5. Approaches to the conceptualization of DDBMs

\begin{tabular}{|c|c|c|c|}
\hline Approaches & Description & Enablers & More representative sources \\
\hline \multirow{7}{*}{ Competitive approach } & Data as a critical asset for & \multirow{7}{*}{ Top management support } & Marchand et al., 2000 \\
\hline & organisations & & Yoo et al., 2010 \\
\hline & & & Westerman \& Bonnet, 2015 Chaudhary \\
\hline & Redefinition of & & et al., 2016 \\
\hline & decision-making through & & Cheah \& Wang, 2017 \\
\hline & management's supportive and & & Tsvetkov \& Chekanov, 2019 Sadowski, \\
\hline & empowering attitude & & 2019 \\
\hline \multirow{4}{*}{ Cultural approach } & \multirow{4}{*}{$\begin{array}{l}\text { Data become driving force to } \\
\text { inform actions, predict } \\
\text { complexity and foster change }\end{array}$} & \multirow{4}{*}{ Data literacy and quality } & Kühne \& Böhmann, 2018 \\
\hline & & & Härting et al., 2018 \\
\hline & & & Kühne et al., 2019 \\
\hline & & & Babar \& Yu, 2019 \\
\hline \multirow{3}{*}{ Strategic approach } & Design of data governance & \multirow{3}{*}{ Data-driven environment } & \\
\hline & & & Cheah \& Wang, 2017 \\
\hline & $\begin{array}{l}\text { Alignment between data and } \\
\text { strategies }\end{array}$ & & Breidbach \& Maglio, 2020 \\
\hline
\end{tabular}

\subsubsection{Benefits and Barriers to DDBM}

All of the studies included in the review process highlight some benefits and barriers to the development of DDBMs that are classified into the technical, organisational and financial dimensions. According to Tong and Mahdzir (2016), the technical dimension concerns the data itself in terms of the levels at which standards and formats are met. In contrast, the organisational dimension embraces the strategic aspects concerning the BM, objectives, strategies and organisational structure. Finally, the financial dimension concerns the resources (i.e., technical, human and financial), procedures and systems needed for processing, managing and maintaining data.

Some articles (34\% of the sample) described the benefits of DDBMs across the above-mentioned dimensions (Table 6). Regarding the benefits linked to the technical dimension, new technologies (i.e., IoT, sensors, clouds or big data analytics) ensure the availability and sharing of data with the right standards and formats. This affects data quantity and quality (Cheah \& Wang, 2017; Benta, Wilberg, Hollauer \& Omer, 2017), thereby guaranteeing more high-performance data analyses (Kühne, Zolnowski, Bornholt \& Böhmann, 2019).

By focusing on the organisational dimension, the benefits of DDBMs are linked to increased competitive advantage since the company leverages data-based knowledge to maintain ongoing growth over competitors, improve market performance and anticipate customer needs (Immonen, Palviainen \& Ovaska, 2014). In addition, DDBMs can change a value proposition, improve the existing one or create a new one (Zolnowski, Christiansen \& Gudat, 2016; Kühne \& Böhmann, 2018). On the one hand, DDBMs lead to improvements in the existing value proposition through the exploitation of data coming from customers, which allows for more customised offerings (Zolnowski \& Böhmann, 2013b; Breinbach \& Maglio, 2020). On the other hand, DDBMs lead to the creation of new value propositions based on 'data-as-a-service', in which the approach is to monetise data that will be used by others to create novel data sets through aggregation or collection (Demirkan \& Delen, 2013). New value propositions can also be based on 'analytics-as-service', in which analytical skills are provided to assist in problem solving (Sorescu, 2017; Breinbach \& Maglio, 2020). The change in a value proposition implies that the DDBM appeals to a broader market demand, thus going beyond the traditional customers (Schaefer et al., 2017). Moreover, the implementation of a DDBM leads to an improved decision-making process since data shape new opportunities for innovative analysis and modelling of solutions. Finally, a DDBM opens new pathways of cooperation within and among companies, which improves the structure of the whole value chain (Härting, Reichstein \& Schad, 2018).

Regarding the benefits linked to the financial dimension, a DDBM allows for the better use of resources with a consequent reduction of costs (Härting et al., 2018). At the same time, a DDBM increases productivity: for instance, data-driven approaches (i.e., dynamic pricing) enable firms to set short time price changes individually to optimise producer surplus. Finally, revenues are also increased since the profit margins on monetised data tend to be very high (Schaefer et al., 2017). 
Table 6. Benefits of DDBMs

\begin{tabular}{|c|c|c|}
\hline Dimensions & Benefits & More representative sources \\
\hline \multirow[t]{3}{*}{ Technical } & Availability of data with the right standards & Cheah and Wang, 2017 \\
\hline & and formats & Benta et al., 2017 \\
\hline & High-performance data analyses & Kühne et al., 2019 \\
\hline \multirow[t]{12}{*}{ Organisational } & Increased competitive advantage & Immonen et al., 2014 \\
\hline & Change in value proposition & Zolnowski \& Böhmann, 2013b \\
\hline & & Zolnowski et al., 2016 \\
\hline & & Schaefer et al., 2017 \\
\hline & & Härting et al., 2018 \\
\hline & & Kühne \& Böhmann, 2018 Breidbach \& \\
\hline & & Maglio, 2020 \\
\hline & & Zaki, 2019 \\
\hline & & Kühne et al., 2019 \\
\hline & New market segments & Schaefer et al., 2017 \\
\hline & Improved decision-making process New & Härting et al., 2018 \\
\hline & ways of cooperation & Babar \& Yu, 2019 \\
\hline \multirow[t]{4}{*}{ Financial } & Better use of resources & Härting et al., 2018 \\
\hline & Reduction of costs & Breidbach \& Maglio, 2020 \\
\hline & Higher productivity & Härting et al., 2018 \\
\hline & Increased revenues & Schaefer et al., 2017 \\
\hline
\end{tabular}

Some articles (42\% of the sample) described barriers to the implementation of DDBMs across the above-mentioned dimensions (Table 7). Regarding the technical dimension, data security was one of the most debated barriers. It concerns both data ownership and measures taken against any attacks to the data (i.e., unauthorised access, modification and deletion; Exner, Stark \& Kim, 2017). These aspects need to be clearly defined not only to determine who will gain from the value created, but also to build and maintain customers' trust (Shantz, 2018). Another barrier to DDBM implementation is the data licence referring to the data collection (how to gather them) and processing (how most effectively to use them). In particular, data can be internally generated by staff, sensors and tracking tools, or they may be obtained from an external source through data acquisition activity performed before or after that the BM has been designed (Kühne et al., 2019). The data process implies understanding of the most beneficial data in terms of information content that can be monetised in a commercial setting (Zaki, 2019). Moreover, data privacy represents a further barrier to DDBM implementation because legal restrictions and social norms governing the use, transfer and processing of personal data must be considered. Since personal data mainly concern customers, transparency in their usage is crucial to avoid losing their trust. The last barrier to DDBM implementation is the data quality affected by the degrees of data consistency and completeness (Kwon et al., 2014). When data do not meet sufficient standards due to missing and unclear information or untrustworthy sources, negative effects on the data-driven value proposition and improper results of analytics activities are the result, triggering an ethical liability for firms (Breidbach \& Maglio, 2020).

By focusing on the organisational dimension, a DDBM's barriers are linked to an increased need for human capabilities and technical facilities enabling access and links to data as well as their interpretation (Janssen, 2012). Thus, changes in human resources' skill sets and technological infrastructure are inevitable. On the one hand, staff activities and job processes need to be redefined, while top management should be able to anticipate and respond to both the threats and opportunities provided by data (Cheah \& Wang, 2017). Otherwise, the DDBM is of low quality, deficient and unsustainable (Smith, 2016; Hossain, 2015). On the other hand, proficient technologies and tools should be utilised for specific tasks to ensure valuable outputs. In this regard, collaboration with customers and partners (i.e., software companies, data providers, etc.) plays an important role given the different resources and knowledge involved in technologies (Schaefer et al., 2017).

Regarding barriers linked to the financial dimension, a DDBM requires huge investments in physical and infrastructural resources and appropriate tools and organisational processes enabling data collection, storage, and analysis (Cheah \& Wang, 2017). In particular, the research and development required to implement a data analytics system is likely to be a high-cost activity. Another financial barrier to DDBM implementation concerns extended payback periods, which companies could suffer from, especially when trying to satisfy the short-term demands of stakeholders (Schaefer et al., 2017). 
Table 7. Barriers to DDBM implementation

\begin{tabular}{|c|c|c|}
\hline Dimensions & Barriers & More representative sources \\
\hline \multirow[t]{12}{*}{ Technical } & & Exner et al., 2017 \\
\hline & Data security & Shantz, 2018 \\
\hline & & Kühne et al., 2019 \\
\hline & & Immonen et al., 2014 \\
\hline & Data licence & Zaki, 2019 \\
\hline & & Kühne et al., 2019 \\
\hline & & Immonen et al., 2014 \\
\hline & Data privacy & Shantz, 2018 \\
\hline & & van de Waerdt, 2020 \\
\hline & & Kühne and Böhmann, 2018 \\
\hline & Data quality & Kühne et al., 2019 \\
\hline & & Breidbach \& Maglio, 2020 \\
\hline \multirow[t]{4}{*}{ Organisational } & Changes in human resources' skill sets and & Cheah \& Wang, 2017 \\
\hline & technogical infrastructure & Kühne et al., 2019 \\
\hline & Need for collaborations with partners & Schaefer et al., 2017 \\
\hline & having specialised knowledge & \\
\hline \multirow[t]{5}{*}{ Financial } & & Exner et al., 2017 \\
\hline & High investments in physical and & Cheah \& Wang, 2017 \\
\hline & infrastructural resources & Schaefer et al. 2017 \\
\hline & & Breidbach \& Maglio, 2020 \\
\hline & Extended Payback & Schaefer et al. 2017 \\
\hline
\end{tabular}

\section{Discussion and Research Agenda}

This SLR highlights that the implementation and development of DDBMs the DDBM are emergent topics in the research fields of business management and the social sciences since a limited number of studies have addressed the intersection of data and BMs. The findings of the thematic analysis are combined in a framework that synthesises the main approaches (i.e., strategic, cultural, and competitive) to developing DDBMs approaches to DDBMs and the relative enablers fostering the adoption of each approach, as well as the main benefits and barriers to the implementation of DDBMs (Figure 6).

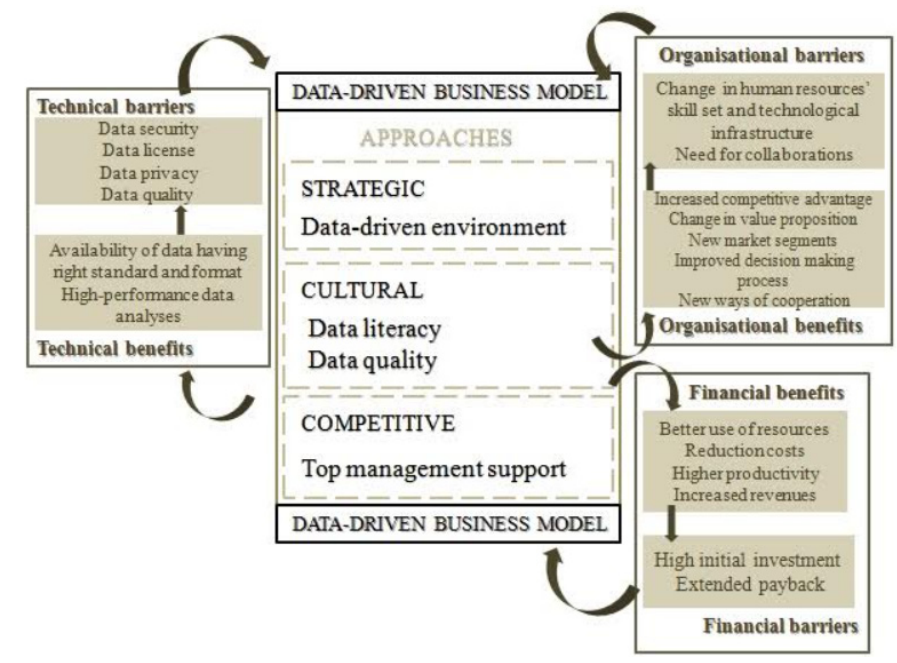

Figure 6. How DDBMs are characterised in the current literature

The set of approaches and enablers arising from the findings have been shown to drive organisations to shift from a traditional 'make-and-sell' BM towards a 'sense-and-act' BM (Köbnick, Velu, \& McFarlane, 2020). Since data have changed the nature of existing products and services, companies should rethink the conventional ways of creating, delivering and capturing value by embracing BMs more suitable for a highly connected world 
(Barquet et al., 2013; Jua, Kim \& Ahn, 2016). This new type of BM should rely heavily on the cognitive aspects linked to the sense making of data to simplify the identification of exploitable knowledge along the entire organisational chain. Thus, the analysis and understanding of data build knowledge that acts as the first engine of benefits, such as the revenue in primis, especially in the digital era (Pauleen \& Wang, 2017). The domino effect of the transferral, sharing and exploitation of new knowledge within the entire organisation is crucial to overcome the barriers to the improvement of competitiveness through data (Ferraris et al., 2019). Furthermore, the knowledge derived from data supports the goals planned (Huesig \& Endres, 2019); this is because it is embedded into the decisions that drive all organisational actions. In sum, a 'sense-and-act' BM optimally consists of a dual nature. On the one hand, the 'sense' component makes the BM a cognitive schema that allows for efficient decision-making in conditions of complexity due to the new paradigm of digitalisation (Massa, Tucci \& Afuah, 2017). On the other hand, the 'act' component makes the BM an activity system aimed at the achievement of an organisation's goals (Zott, Amil \& Massa, 2011).

In the following, some gaps and future research directions are identified, as suggested by the descriptive and thematic analyses of the literature on DDBMs.

\section{Research direction 1: Carrying out empirical research}

Since much of the current literature is conceptual, an important step in the process of understanding this phenomenon is the development of empirical observations of DDBMs. This could contribute to filling the 'deployment gap', which refers to the paradox between huge opportunities provided by data and the lack of DDBMs actually deployed across industries (Heudecker \& Kart, 2014; Chen, Sch'tz, Kazman \& Matthes, 2017). The availability of empirical research could drive the development of new BMs or the evolution of existing BMs into DDBMs, helping many organisations to overcome a limbo in which their will to adopt data is opposed to their inability to do so (Chen, Kazman \& Matthes, 2015; Schüritz \& Satzger, 2016). This suggests that future research should not be static in nature, thereby allowing for changes over time to be captured through longitudinal studies.

\section{Research direction 2: Addressing emerging countries}

The literature on DDBMs comes mainly from advanced economies and reflects the view that datatisation is an opportunity for designing BMs able to generate new competitive advantages in mature settings. Nevertheless, an interesting research area is related to the role of DDBMs in emerging countries. The expected impacts are specific insights into the DDBMs specific developments of DDBMs because of the differences in national regulations, cultural views on privacy and the lack of competences and infrastructures (i.e., inconsistent power supplies and spotty internet access) (Bram, Warwick-Clark, Obeysekare \& Mehta, 2015; Rambe \& Moeti, 2017; Ciasullo, Montera, Cucari \& Polese, 2020).

\section{Research direction 3: Increase of multi- and inter-disciplinarity}

While the DDBM literature is dynamic, it has developed along narrow and fragmented disciplinary lines. In particular, existing studies have emerged in separate disciplinary silos and tackle separate portions of knowledge, despite this research field involving many collaborating disciplines (Emani, Cullot \& Nicolle, 2015; Hu \& Zhang, 2017). Thus, our review sheds light on the need for a systematic inventory of the interconnections with other fields, guiding the avoidance of myopia by looking at the totality of the phenomenon to promote understanding and development of DDBM research. In addition, we call for conceptual pluralism and the use of well-established theories from adjacent mature fields, which would endow DDBM research with higher-order components.

\section{Research direction 4: Ecosystem perspective}

When investigating DDBMs, previous research has tended to focus on the perspective of the focal organisation. Thus, future studies should examine DDBMs through a holistic, multi-actor lens and emphasise the systemic, dynamic and contextual aspects of the phenomenon as influenced by the interactions between actors (Vargo \& Lusch, 2011; Tronvoll, 2017). This perspective could broaden the scope of DDBM research beyond the firm-centric model to explore the collaboration between data users, data suppliers and facilitators, and different stakeholders at the individual and societal levels. Hence, it is important to know and define actors' roles and responsibilities in DDBMs, together with the potential network effects between them (Kühne et al., 2019; Yablonsky, 2019).

\section{Research direction 5: Cross-fertilisation between data, artificial intelligence and machine learning in BMs}

The role played by big data, analytics and generic digital technologies is highlighted in this research field. Conversely, artificial intelligence (AI) and machine learning have not been adequately investigated, despite the 
fact that they could be of interest in DDBM research. Specifically, these technologies act as the catalyst of BM innovation (Lee, Suh, Roy \& Baucus, 2019), and innovation through them is powered by data. Thus, AI and machine learning enable new and improved ways of using data in BMs (Yablonsky, 2019). In any event, future research should broaden the focus from the study of 'mere' technology to the human and social sides of BMs' datatisation. Thus, technological tools do not automatically imply a DDBM has been realised successfully, but rather, the ways in which people activate them through flexible skills and knowledge make the difference.

\section{Research direction 6: Addressing ethical issues}

Ethical issues associated with the deployment of DDBMs deserve greater emphasis in the literature since power, control, and influence over individuals are mainly linked to the unethical use of big data due to the predatory data culture of many organisations (Wixom \& Ross, 2017; Someh, Davern, Breidbach \& Shanks, 2019). Beyond privacy, a promising path for future research lies in the idea that data sharing is not inherently transparent: in fact, individuals do not know if, why or with whom the sharing will occur (Barocas \& Nissenbaum, 2014), and their anonymity is not preserved over time (Zuboff, 2015).

\section{Conclusion}

\subsection{Theoretical and Practical Implications}

This paper provides a synthesis of the current conceptual and empirical literature on the emerging phenomenon of DDBMs. Since research focusing on the bridge between data and BM is scarce, a theoretical contribution of this study pertains to the identification of the current state of the art within the context of data and analytics in BMs. Another implication of our review lies in the harmonisation of the existing knowledge in a multiperspective framework that not only conceptualises the main characteristics of DDBMs but also offers theoretical guidance for advancing our understanding of them as a phenomenon. In fact, the final conceptual contribution of the paper rests in the identification of specific gaps in the managerial literature that lead to the description of six directions for future research in the area.

With regard to the implications for practice, the study proposes some relevant insights for managers, which highlight the potential of the digital revolution to deeply change management and decision-making practices according to a new data-driven culture (Chen, Chiang \& Storey, 2012). The work supports many organisations in overcoming a limbo stage: in recognising data as 'the new oil' (Hartmann et al., 2016, p. 1382) for competitiveness, there is the will to collect, analyse and interpretate data; unfortunately, this is often opposed to the inability to turn data into valuable knowledge and thereby profit. Thus, a range of approaches (i.e., competitive, cultural and strategic) is suggested to drive managers when designing new BMs based on data or shifting the existing BMs into DDBMs. In addition, we identify specific enablers (i.e, top management support, data literacy, data quality and data-driven environments) that managers should activate to successfully implement one or more of the approaches chosen. Beyond these approaches, the review provides a detailed list of the benefits and barriers related to DDBMs that managers should consider, as they affect the future value generated by the datatisation of BMs. For this reason, the benefits and barriers are identified at a granular level through various dimensions (i.e., technical, organisational and financial).

\subsection{Limitations and Further Research}

Despite the value of the findings presented here, the paper has some limitations. First, we focused on studies written in English and excluded various types of publications, such as books and reports. These choices might have circumscribed our findings, which can be complemented by future studies examining these other documents. Second, the findings of SRL depend on the reviewers' educational backgrounds. Thus, future works should involve interdisciplinary research teams to shed light on multifaceted aspects of the phenomenon. In sum, this paper is an exploratory step that paves the way for other empirical papers (i.e., qualitative, quantitative and mixed) to move forward with the evidence herein that emerged.

\section{References}

Abbasi, A., Sarker, S., \& Chiang, R. H. (2016). Big data research in information systems: Toward an inclusive research agenda. Journal of the Association for Information Systems, 17(2), 3. https://doi.org/10.17705/1jais.00423

Ahlemeyer-Stubbe, A., \& Müller, A. (2020). How to leverage internet of things data to generate benefits for sales and marketing. Applied Marketing Analytics, 5(3), 233-242.

Amini, M., Hariri, N., Sales, M. G., Babalhavaeji, F., \& Taheri, S. M. (2020). Studying on Data-Driven Business Model Patterns. Iranian Journal of Information Processing and Management. 
Amit, R., \& Zott, C. (2001). Value creation in e-business. Strategic Management Journal, 22(6/7), 493-520. https://doi.org/10.1002/smj.187.

Applegate, L. M. (2001). Emerging e-business models: lessons from the field. Harvard Business School, 9-801-172.

Arnold, C., Kiel, D., \& Voigt, K. I. (2020). How the Industrial Internet of Things Changes Business Models in Different Manufacturing Industries. In Digital Disruptive Innovation (pp. 139-168).

Babar, Z., \& Yu, E. (2019, October). Digital Transformation-Implications for Enterprise Modeling and Analysis. In 2019 IEEE 23rd International Enterprise Distributed Object Computing Workshop (EDOCW) (pp. 1-8). IEEE. https://doi.org/10.1109/EDOCW.2019.00015

Baesens, B., Bapna, R., Marsden, J. R., Vanthienen, J., \& Zhao, J. L. (2016). Transformational issues of big data and analytics in networked business. MIS Quarterly, 40(4). https://doi.org/10.25300/MISQ/2016/40:4.03

Bales, R. F., Krippendorff, K., \& Bock, M. A. (2009). Interaction process analysis. In Krippendorff, K \& Bock, M. A. (Eds.), The Content Analysis Reader, (pp. 75-83). SAGE.

Barocas, S., \& Nissenbaum, H. (2014). Big data's end run around anonymity and consent. In Lane G., Stodden V., Bender S. \& Nissenbaum, H. (Eds.), Privacy, big data, and the public good: Frameworks for engagement, 1 , (pp. 44-75).

Barquet, A. P. B., de Oliveira, M. G., Amigo, C. R., Cunha, V. P., \& Rozenfeld, H. (2013). Employing the business model concept to support the adoption of product-service systems (PSS). Industrial Marketing Management, 42, 693-704. https://doi.org/10.1016/j.indmarman.2013.05.003

Benta, C., Wilberg, J., Hollauer, C., \& Omer, M. (2017). Process model for data-driven business model generation. In DS 87-2 Proceedings of the 21st International Conference on Engineering Design (ICED 17) Vol 2: Design Processes, Design Organisation and Management, Vancouver, Canada, 21-25.08. 2017 (pp. 347-356).

Berger, R. (2015). The digital transformation of industry. The study commissioned by the Federation of German Industries (BDI), Munich. Retrieved http://www.rolandberger.com/publications/publication_pdf/roland_berger_digital_transformation_of_indust ry_20150315

Bocken, N. M., Short, S. W., Rana, P., \& Evans, S. (2014). A Literature and Practice Review to Develop Sustainable Business Model Archetypes. Journal of Cleaner Production, (65), 42-56. https://doi.org/10.1016/j.jclepro.2013.11.039

Bouwman, H., de Reuver, M., \& Shahrokh, N. (2017). The impact of digitalisation on business models: How IT artefacts, social media, and big data force firms to innovate their business model. 14th International Telecommunications Society (ITS) Asia-Pacific Regional Conference, Kyoto.

Bram, J. T., Warwick-Clark, B., Obeysekare, E., \& Mehta, K. (2015). Utilization and monetization of healthcare data in developing countries. Big Data, 3(2), 59-66. https://doi.org/ 10.1089/big.2014.0053

Breidbach, C. F., \& Maglio, P. (2020). Accountable algorithms? The ethical implications of data-driven business models. Journal of Service Management. https://doi.org/ 10.1108/josm-03-2019-0073

Breitfuss, G., Fruhwirth, M., Pammer-Schindler, V., Stern, H., \& Dennerlein, S. (2019). The data-driven business value Matrix-A classification scheme for data-driven business models. Proceedings of Bled eConference ( $\mathrm{p}$. 19).

Brynjolfsson, E., Hitt, L. M., \& Kim, H. H. (2011). Strength in numbers: How does data-driven decision making affect firm performance? https://dx.doi.org/10.2139/ssrn.1819486

Burmeister, C., Lüttgens, D. \& Piller, F.T. (2016), 'Business model innovation for Industrie 4.0: why the "Industrial Internet" mandates a new perspective on innovation'. Die Unternehmung, 70(2), 124-152. http://dx.doi.org/10.2139/ssrn.2571033

Carlson, J., Fosmire, M., Miller, C. C., \& Nelson, M. S. (2011). Determining data information literacy needs: A study of students and research faculty. Libraries and the Academy. 11(2), 629-657. https://doi.org/10.1353/pla.2011.0022

Chaudhary, R., Pandey, J. R., \& Pandey, P. (2015, October). Business model innovation through big data. Proceedings of 2015 International Conference on Green Computing and Internet of Things (ICGCIoT) (pp. 


\section{9-263). https://doi.org/10.1109/ICGCIoT.2015.7380469}

Cheah, S., \& Wang, S. (2017). Big data-driven business model innovation by traditional industries in the Chinese economy. Journal of Chinese Economic and Foreign Trade Studies. 10(3), 229-251. https://doi.org/10.1108/jcefts-05-2017-0013

Chen, H. M., Kazman, R., \& Matthes, F. (2015). Demystifying big data adoption: Beyond IT fashion and relative advantage. Proceedings of DIGIT 2015. Paper 4. https://aisel.aisnet.org/digit2015/4

Chen, H. M., Schütz, R., Kazman, R., \& Matthes, F. (2017). How Lufthansa Capitalized on Big Data for Business Model Renovation. MIS Quarterly Executive, 16(1).

Chen, H., Chiang, R. H., \& Storey, V. C. (2012). Business intelligence and analytics: From big data to big impact. MIS quarterly, 1165-1188. https://doi.org/https://doi.org/10.2307/41703503

Chen, M., Mao, S., Zhang, Y., \& Leung, V. C. (2014). Big data: related technologies, challenges and future prospects (Vol. 96). Heidelberg: Springer.

Chesbrough, H. (2010). Business model innovation: opportunities and barriers. Long Range Planning, 43(2-3), 354-363. https://doi.org/10.1016/j.lrp.2009.07.010

Ciasullo, M. V., Montera, R., Cucari, N., \& Polese, F. (2020). How an international ambidexterity strategy can address the paradox perspective on corporate sustainability: Evidence from Chinese emerging market multinationals. Business Strategy and the Environment, 29(5), 2110-2129. https://doi.org/ 10.1002/bse.2490

Ciasullo, M. V., Polese, F., Montera, R., \& Carrubbo, L. (2021). A digital servitization framework for viable manufacturing companies. Journal of Business and Industrial Marketing, forthcoming. https://doi.org/10.1108/JBIM-07-2020-0349

Cooper, H. M. (1998). Synthesizing research: A guide for literature reviews (Vol. 2). Sage.

Coyle, D., \& Nguyen, D. (2019). Cloud Computing, Cross-Border Data Flows and New Challenges for Measurement in Economics. National Institute Economic Review, 249(1), 30-38. https://doi.org/10.1177/002795011924900112

Demirkan, H., \& Delen, D. (2013). Leveraging the capabilities of service-oriented decision support systems: Putting analytics and big data in cloud. Decision Support Systems, 55(1), 412-421. https://doi.org/10.1016/j.dss.2012.05.048

Emani, C. K., Cullot, N., \& Nicolle, C. (2015). Understandable big data: a survey. Computer science review, 17, 70-81. https://doi.org/10.1016/j.cosrev.2015.05.002

Engelbrecht, A., Gerlach, J., \& Widjaja, T. (2016). Understanding the Anatomy of Data-Driven Business Models- Towards an Empirical Taxonomy. Proceedings of the 24th European Conference on Information Systsms, Istanbul, Turkey, 1-12. https://aisel.aisnet.org/ecis2016_rp/128

Exner, K., Smolka, E., Blüher, T., \& Stark, R. (2019). A method to design Smart Services based on information categorization of industrial use cases. Procedia CIRP, 83, 77-82. https://doi.org/10.1016/j.procir.2019.02.143

Exner, K., Stark, R., \& Kim, J. Y. (2017, June). Data-driven business model a methodology to develop smart services. In 2017 International Conference on Engineering, Technology and Innovation (ICE/ITMC) (pp. 146-154). IEEE. https://doi.org/10.1109/ICE.2017.8279882

Faroukhi, A. Z., El Alaoui, I., Gahi, Y., \& Amine, A. (2020). An Adaptable Big Data Value Chain Framework for End-to-End Big Data Monetization. Big Data and Cognitive Computing, 4(4), 34. https://doi.org/10.3390/bdcc4040034

Ferraris, A., Mazzoleni, A., Devalle, A., \& Couturier, J. (2019). Big data analytics capabilities and knowledge management: Impact on firm performance. Management Decision, 57(8), 1923-1936. https://doi.org/10.1108/MD-07-2018-0825

Gimpel, G. (2020). Bringing dark data into the light: Illuminating existing IoT data lost within your organization. Business Horizons, 63(4), 519-530.

Grandinetti, R., Ciasullo, M. V., Paiola, M., \& Schiavone, F. (2020). Fourth industrial revolution, digital servitization and relationship quality in Italian B2B manufacturing firms: an exploratory study. TQM Journal, 32(4), 647-671. 
Günther, W. A., Mehrizi, M. H. R., Huysman, M., \& Feldberg, F. (2017). Debating big data: A literature review on realizing value from big data. The Journal of Strategic Information Systems, 26(3), 191-209. https://doi.org/10.1016/j.jsis.2017.07.003

Gupta, M., \& George, J. F. (2016). Toward the development of a big data analytics capability. Information \& Management, 53(8), 1049-1064. https://doi.org/10.1016/j.im.2016.07.004

Härting, R. C., Reichstein, C., \& Schad, M. (2018). Potentials of Digital Business Models-Empirical investigation of data driven impacts in industry. Procedia Computer Science, 126, 1495-1506. https://doi.org/10.1016/j.procs.2018.08.121

Hartmann, P. M., Zaki, M., Feldmann, N., \& Neely, A. (2014). Big data for big business? A taxonomy of data-driven business models used by start-up firms. Cambridge Service Alliance, 1-29.

Hartmann, P. M., Zaki, M., Feldmann, N., \& Neely, A. (2016). Capturing value from big data-a taxonomy of data-driven business models used by start-up firms. International Journal of Operations \& Production Management., (36)10, 1382-1406. https://doi.org/10.1108/IJOPM-02-2014-0098

He, L., Xue, M., \& Gu, B. (2020). Internet-of-things enabled supply chain planning and coordination with big data services: Certain theoretic implications. Journal of Management Science and Engineering, 5(1), 1-22. https://doi.org/10.1016/j.jmse.2020.03.002

Heudecker, N., \& Kart, L. (2014). Survey Analysis: Big Data Investment Grows but Deployments Remain Scarce in 2014. Stamford: Gartner.

Hmoud, A. Y., Salim, J., \& Yaakub, M. R. (2020). Platformisation of Mobile Operators Business Model: A Proposition Using Design Science Approach and Grounded Theory Principles. Environment, 4(6). https://doi.org/10.18517/ijaseit.10.2.7710

Hossain, M. A., Dwivedi, Y. K., \& Rana, N. P. (2016). State-of-the-art in open data research: Insights from existing literature and a research agenda. Journal of organizational Computing and Electronic Commerce, 26(1-2), 14-40. https://doi.org/10.1080/10919392.2015.1124007

Hu, J., \& Zhang, Y. (2017). Discovering the interdisciplinary nature of Big Data research through social network analysis and visualization. Scientometrics, 112(1), 91-109. https://doi.org/10.1007/s11192-017-2383-1

Huesig, S., \& Endres, H. (2019). Exploring the digital innovation process. European Journal of Innovation Management, 22(2), 302-314. https://doi.org/10.1108/EJIM- 02-2018-0051

Hunke, F., Seebacher, S., Schüritz, R., \& Illi, A. (2017, July). Towards a process model for data-driven business model innovation. In 2017 IEEE 19th Conference on Business Informatics (CBI) (Vol. 1, pp. 150-157). https://doi.org/10.1109/CBI.2017.43

Ibarra, D., Ganzarain, J., \& Igartua, J.I. (2018). Business model innovation through Industry 4.0: a review. Procedia Manufacturing, 22, 4-10. https://doi.org/10.1016/j.promfg.2018.03.002

Immonen, A., Palviainen, M., \& Ovaska, E. (2014). Requirements of an open data based business ecosystem. IEEE access, 2, 88-103. https://doi.org/10.1109/ACCESS.2014.2302872

Isabelle, D., Westerlund, M., Mane, M., \& Leminen, S. (2020). The Role of Analytics in Data-Driven Business Models of Multi-Sided Platforms: An exploration in the food industry. Technology Innovation Management Review, 10(7). https://doi.org/10.22215/timreview/1371.

Janssen, M., van der Voort, H., \& Wahyudi, A. (2017). Factors influencing big data decision-making quality. Journal of Business Research, 70, 338-345. https://doi.org/10.1016/j.jbusres.2016.08.007.

Ju, J., Kim, M. S., \& Ahn, J. H. (2016). Prototyping business models for IoT service. Procedia Computer Science, 91, 882-890. https://doi.org/10.1016/j.procs.2016.07.106.

Kiel, D., Arnold, C., \& Voigt, K. I. (2017). The influence of the Industrial Internet of Things on business models of established manufacturing companies - a business level perspective. Technovation, 68(September), 4-19. https://doi.org/10.1016/j.technovation.2017.09.003

Köbnick, P., Velu, C., \& McFarlane, D. (2020). Preparing for Industry 4.0: digital business model innovation in the food and beverage industry. International Journal of Mechatronics and Manufacturing Systems, 13(1), 59. https://doi.org/10.1504/IJMMS.2020.108334

Krämer, J., \& Wohlfarth, M. (2018). Market power, regulatory convergence, and the role of data in digital markets. Telecommunications Policy, 42(2), 154-171. https://doi.org/10.1016/j.telpol.2017.10.004 
Kühne, B., \& Böhmann, T. (2018). Requirements for Representing Data-Driven Business Models-Towards Extending the Business Model Canvas. Proceedings of Twenty-fourth Americas Conference on Information Systems. New Orleans.

Kühne, B., \& Böhmann, T. (2019). Data-driven business models-building the bridge between data and value. Proceedings of Twenty-Seventh European Conference on Information Systems (ECIS2019), Stockholm-Uppsala, Sweden, 1-16. https://aisel.aisnet.org/ecis2019_rp/167

Kühne, B., Zolnowski, A., Bornholt, J., \& Böhmann, T. (2019, June). Making Data Tangible for Data-driven Innovations in a Business Model Context. In AMCIS.

Kwon, O., Lee, N., \& Shin, B. (2014). Data quality management, data usage experience and acquisition intention of big data analytics. International Journal of information management, 34(3), 387-394. https://doi.org/10.1016/j.ijinfomgt.2014.02.002

Lange, H. E., \& Drews, P. (2020, June). From Ideation to Realization: Essential Steps and Activities for Realizing Data-Driven Business Models. In 2020 IEEE 22nd Conference on Business Informatics (CBI) (Vol. 2, pp. 20-29). IEEE. https://doi.org/ 10.1109/CBI49978.2020.10054

LaValle, S., Lesser, E., Shockley, R., Hopkins, M. S., \& Kruschwitz, N. (2011). Big data, analytics and the path from insights to value. MIT Sloan Management Review, 52(2), 21-32.

Lee, J., Suh, T., Roy, D., \& Baucus, M. (2019). Emerging technology and business model innovation: the case of artificial intelligence. Journal of Open Innovation: Technology, Market, and Complexity, 5(3), 44. https://doi.org/10.3390/joitmc5030044

Linares-Espinós, E., Hernández, V., Domínguez-Escrig, J. L., Fernández-Pello, S., Hevia, V., Mayor, J., ... \& Ribal, M. J. (2018). Methodology of a systematic review. Actas Urológicas Españolas (English Edition), 42(8), 499-506. https://doi.org/10.1016/j.acuroe.2018.07.002

Lokshina, I. V., Lanting, C. J., \& Durkin, B. J. (2018). IoT-and big data-driven data analysis services for third parties, strategic implications and business opportunities. International Journal of Social Ecology and Sustainable Development (IJSESD), 9(3), 34-52. https://doi.org/1 0.4018/IJSESD.2018070103

Mandinach, E. B., \& Honey, M. (Eds.). (2008). Data-driven school improvement: Linking data and learning. Teachers College Press.

Mandinach, E. B., Honey, M., Light, D., \& Brunner, C. (2008). A conceptual framework for data-driven decision making. In Mandinach, E. B., \& Honey, M. (Eds.), Data-driven school improvement: Linking data and learning, (pp. 13-31).

Manesh, M. F., Pellegrini, M. M., Marzi, G., \& Dabic, M. (2020). Knowledge management in the fourth industrial revolution: Mapping the literature and scoping future avenues. IEEE Transactions on Engineering Management, 68(1), 289-300. https://doi.org/10.1109/TEM.2019.2963489

Manyika, J., Chui, M., Brown, B., Bughin, J., Dobbs, R., Roxburgh, C., \& Hung Byers, A. (2011). Big data: The next frontier for innovation, competition, and productivity. McKinsey Global Institute.

Massa, L., Tucci, C. L., \& Afuah, A. (2017). A critical assessment of business model research, Academy of Management Annals, 11(1), 73-104. https://doi.org/10.5465/annals.2014.0072

Mikalef, P., Pappas, I., Krogstie, J., \& Pavlou, P. A. (Eds.). (2020). Big data and business analytics: A research agenda for realizing business value. Elsevier.

Moher, D., Liberati, A., Tetzlaff, J., Altman, D. G. (2009), Preferred reporting items for systematic reviews and meta-analyses: the PRISMA statement, Annals of internal medicine, 151(4), 264-269. https://doi.org/10.1371/journal.pmed.1000097

Moher, D., Shamseer, L., Clarke, M., Ghersi, D., Liberati, A., Petticrew, M., .. \& Stewart, L. A. (2015). Preferred reporting items for systematic review and meta-analysis protocols (PRISMA-P) 2015 statement. Systematic reviews, 4(1), 1-9. https://doi.org/10.1186/2046-4053-4-1

Müller, J.M. (2019). Business model innovation in small- and medium-sized enterprises: strategies for Industry 4.0 providers and users. Journal of Manufacturing Technology Management, 124-152, https://doi.org/10.1108/JMTM-01-2018-0008

Müller, J. M., Buliga, O., \& Voigt, K. I. (2018). Fortune favors the prepared: how SMEs approach business model innovations in Industry 4.0. Technological Forecasting \& Social Change, 132(3), 2-17. 
https://doi.org/10.1016/j.techfore.2017.12.019

Norris, M., Oppenheim, C. (2007). Comparing alternatives to the Web of Science for coverage of the social sciences' literature. $J$ Informetr, 1(2),161-169. https://doi.org/10.1016/j.joi.2006.12.001

Nylund, P. A., Ferras-Hernandez, X., \& Brem, A. (2020). Automating profitably together: Is there an impact of open innovation and automation on firm turnover? Review of Managerial Science, 14(1), 269-285. https://doi.org/10.1007/s11846-018-0294-z

Opresnik, D., \& Taisch, M. (2015). The value of big data in servitization. International journal of production economics, 165, 174-184. https://doi.org/10.1016/j.ijpe.2014.12.036

Osterwalder, A., \& Pigneur, Y. (2010). Business model generation: a handbook for visionaries, game changers, and challengers. John Wiley \& Sons.

Paiola, M., \& Gebauer, H. (2020). Internet of things technologies, digital servitization and business model innovation in BtoB manufacturing firms. Industrial Marketing Management, 89, 245-264. https://doi.org/10.1016/j.indmarman.2020.03.009

Pauleen, D.J., \& Wang, W.Y. (2017). Does big data mean big knowledge? KM perspectives on big data and analytics. Journal of Knowledge Management, 21(1), 1-6. https://doi.org/10.1108/JKM-08-2016-0339

Polese, F., Botti, A., Grimaldi, M., Monda, A., Vesci, M. (2018), Social innovation in smart tourism ecosystems: How technology and institutions shape sustainable value cocreation. Sustainability, 10(1), 140. https://doi.org/10.3390/su10010140

Rambe, P., \& Moeti, M. (2017). Disrupting and democratising higher education provision or entrenching academic elitism: Towards a model of MOOCs adoption at African universities. Educational Technology Research and Development, 65(3), 631-651. https://doi.org/10.1007/s11423-016-9500-3

Robinson, P., \& Lowe, J. (2015). Literature reviews vs systematic reviews. Australian and New Zealand journal of public health, 39(2), 103-103. https://doi.org/10.1111/1753-6405.12393

Ruan, J., Hu, X., Huo, X., Shi, Y., Chan, F. T., Wang, X., \& Zhao, X. (2020). An IoT-based E-business model of intelligent vegetable greenhouses and its key operations management issues. Neural Computing and Applications, 1-16. https://doi.org/10.1007/s00521-019-04123-x

Sadowski, J. (2019). When data is capital: Datafication, accumulation, and extraction. Big Data \& Society, 6(1), https://doi.org/10.1177/2053951718820549

Saebi, T., Lien, L., \& Foss, N. J. (2017). What drives business model adaptation? The impact of opportunities, threats and strategic orientation. Long Range Planning, 50(5), 567-581. https://doi.org/10.1016/j.lrp.2016.06.006

Schaefer, D., Walker, J., \& Flynn, J. (2017). A data-driven business model framework for value capture in Industry 4.0. Advances in Transdisciplinary Engineering, 6, 245-250. https://doi.org/10.3233/978-1-61499-792-4-245

Schmidt, R., Möhring, M., Maier, S., Pietsch, J., \& Härting, R. C. (2014, May). Big data as strategic enabler-insights from central european enterprises. In International Conference on Business Information Systems (pp. 50-60). Springer, Cham. https://doi.org/10.1007/978-3-319-06695-0_5

Schrage, M. (2016). How the big data explosion has changed decision making. Harvard Business Review, 25.

Schroeder R (2016). Big data business models: Challenges and opportunities. Cogent Social Sciences, 2, 1166924. https://doi.org/10.1080/23311886.2016.1166924

Schüritz, R., \& Satzger, G. (2016). Patterns of Data-Infused Business Model Innovation, in Proceedings of IEEE 18th Conference on Business Informatics (CBI), no. November, pp. 1-10. https://doi.org/10.1109/CBI.2016.23

Schüritz, R., Seebacher, S., \& Dorner, R. (2017). Capturing value from data: Revenue models for data-driven services. In Proceedings of the 50th Hawaii International Conference on System Sciences. http://doi.org/10.24251/HICSS.2017.648

Seiberth, G., \& Gründinger, W. (2018). Data-driven business models in connected cars, mobility services and beyond. Retrieved from https://bvdw.org/datadrivenbusinessmodels/

Shantz, A. S. (2018). Big data, bigger questions: Data-based business models and their implications for organizational boundaries, data governance, and society. Research in the Sociology of Organizations, 57, 


\section{5-329. https://doi.org/10.1108/S0733-558X20180000057012}

Sharma, R., Mithas, S., \& Kankanhalli, A. (2014). Transforming decision-making processes: a research agenda for understanding the impact of business analytics on organisations. European Journal of Information Systems, 23(4), 433-441. https://doi.org/ 10.1057/ejis.2014.17

Smith, G., Ofe, H. A., \& Sandberg, J. (2016, January). Digital service innovation from open data: exploring the value proposition of an open data marketplace. In 2016 49th Hawaii International Conference on System Sciences (HICSS) (pp. 1277-1286). IEEE. https://doi.org/10.1109/HICSS.2016.162

Someh, I.A., Davern, M., Breidbach, C.F. and Shanks, G. (2019). Ethical issues in big data analytics: a stakeholder perspective, Communications of the Association for Information Systems, 34(44), 718-747. https://doi.org/10.17705/1CAIS.04434

Sorescu, A. (2017). Data-driven business model innovation. Journal of Product Innovation Management, 34(5), 691-696. https://doi.org/10.1111/jpim.12398

Stewart, D.W., \& Zhao, Q. (2000). Internet marketing, business models, and public policy. Journal of Public Policy \& Marketing, 19(2), 287-296, https://doi.org/10.1509/jppm.19.2.287.17125

Svahn, F., Mathiassen, L., \& Lindgren, R. (2017). Embracing digital innovation in incumbent firms: How Volvo cars managed competing concerns. MIS Quarterly, 41(1), 239-253.

Teece, D. J. (2018). Business models and dynamic capabilities. Long Range Planning, 51(1), 40-49. https://doi.org/10.1016/j.lrp.2017.06.007

Tong, W., \& Mahdzir, A. M. (2016). Open Data Innovation: Business Models, Taxonomies and Challenges: Insights from Existing Literature and Research Agenda. Innovation and management, 1546.

Tongur, S., \& Engwall, M. (2014). The business model dilemma of technology shifts. Technovation, 34(9), 525-535. https://doi.org/10.1016/j.technovation.2014.02.006

Trabucchi, D., \& Buganza, T. (2019). Data-driven innovation: switching the perspective on Big Data. European Journal of Innovation Management. https://doi.org/10.1108/EJIM-01-2018-0017

Tranfield, D., Denyer, D., Smart, P. (2003). Towards a methodology for developing evidence-informed management knowledge by means of systematic review, British journal of management, 14(3), 207-222. https://doi.org/ 10.1111/1467-8551.00375

Tronvoll, B. (2017). The actor: The key determinator in service ecosystems, Systems, 2(5), 38. https://doi.org/10.3390/systems502003

Tsvetkov, N., \& Chekanov, A. (2019). The data dilemma: how availability can threaten the competitive advantage of data-based firms, Journal of Business Strategy. https://doi.org/10.1108/JBS-08-2019-0165

Urbinati, A., Bogers, M., Chiesa, V., \& Frattini, F. (2019). Creating and capturing value from Big Data: A multiple-case study analysis of provider companies. Technovation, 84, 21-36. https://doi.org/10.1016/j.technovation.2018.07.004

Van de Waerdt, P. J. (2020). Information asymmetries: recognizing the limits of the GDPR on the data-driven market. Computer Law \& Security Review, 38, 1-18. https://doi.org/10.1016/j.clsr.2020.105436

Vargo, S.L. and Lusch, R.F. (2011). It's all B2B and beyond: toward a systems perspective of the market. Industrial Marketing Management, 40(2), 181-187. https://doi.org/10.1016/j.indmarman.2010.06.026

Velu, C., \& Stiles, P. (2013). Managing decision-making and cannibalization for parallel business models. Long Range Planning, 46(6), 443-458. https://doi.org/10.1016/j.lrp.2013.08.003

Warner, K. S., \& Wäger, M. (2019). Building dynamic capabilities for digital transformation: An ongoing process of strategic renewal. Long Range Planning, 52(3), 326-349. https://doi.org/10.1016/j.lrp.2018.12.001

Westerman, G., \& Bonnet, D. (2015). Revamping your business through digital transformation. MIT Sloan Management Review, 56(3), 10.

Wiener, M., Saunders, C., \& Marabelli, M. (2020). Big-data business models: A critical literature review and multiperspective research framework. Journal of Information Technology, 35(1), 66-91. https://doi.org/10.1177/0268396219896811 
Wixom, B. H., \& Ross, J. W. (2017), How to monetize your data. MIT Sloan Management Review, 58(3), 9-13. Retrieved from http://www.gartner.com/doc/2841519/survey-analysis-big-datainvestment

Yablonsky, S. (2019). Multidimensional data-driven artificial intelligence innovation. Technology innovation management review, 9(12), 16-28. https://doi.org/10.22215/timreview/1288

Yoo, Y., Lyytinen, K. J., Boland, R. J., \& Berente, N. (2010). The next wave of digital innovation: Opportunities and challenges. Report on the research workshop "Digital Challenges in Innovation Research". https://dx.doi.org/10.2139/ssrn.1622170

Zaki, M. (2019). Digital transformation: harnessing digital technologies for the next generation of services, Journal of Services Marketing, 33(4), 429-435. https://doi.org/10.1108/JSM-01-2019-0034

Zolnowski, A., \& Böhmann, T. (2013, January). Customer integration in service business models. Proceedings of 2013 46th Hawaii International Conference on System Sciences (pp. 1103-1112). IEEE. https://doi.org/10.1109/HICSS.2013.158

Zolnowski, A., Christiansen, T., \& Gudat, J. (2016). Business model transformation patterns of data-driven innovations. Research Papers, 146. https://aisel.aisnet.org/ecis2016_rp/146

Zott, C., Amil, R., \& Massa, L. (2011). The business model: recent developments and future research. Journal of Management, 37(4), 1019-1042. https://doi.org/10.1177/0149206311406265

Zuboff, S. (2015). Big other: surveillance capitalism and the prospects of an information civilization. Journal of Information Technology. (30)1, 75-89. https://doi.org/10.1057/jit.2015.5

Appendix A. Publications included in the review

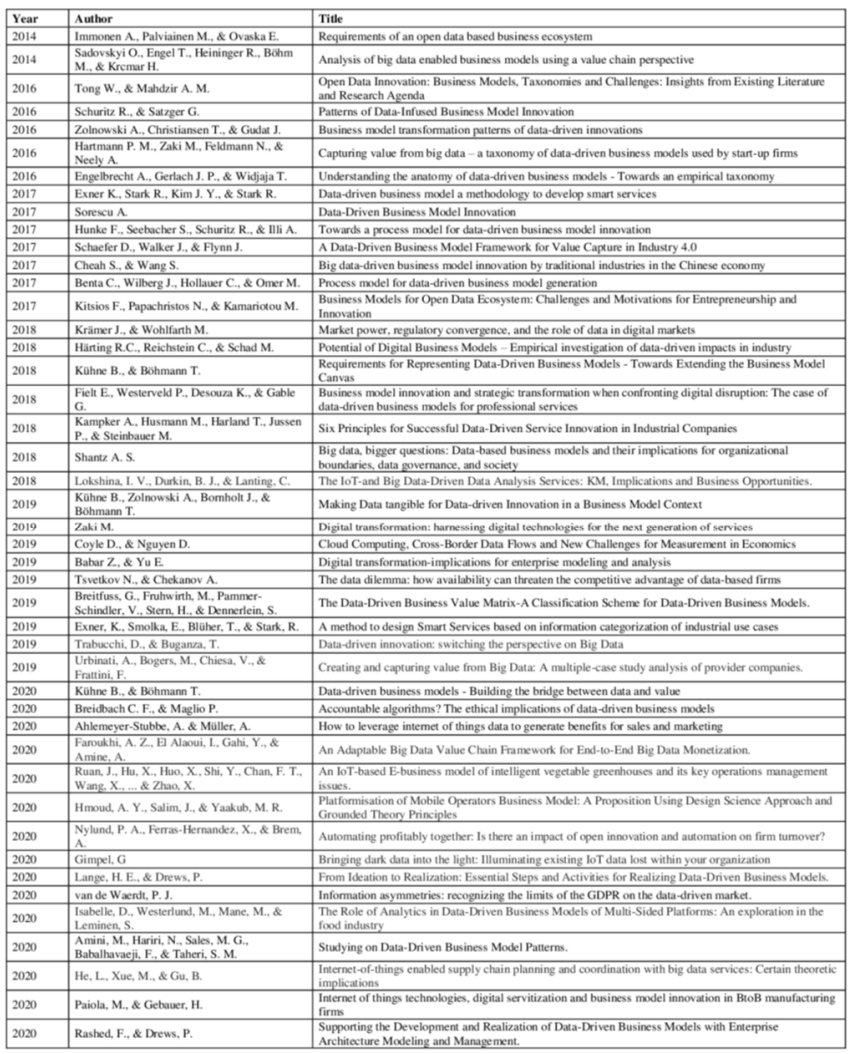

\section{Copyrights}

Copyright for this article is retained by the author(s), with first publication rights granted to the journal.

This is an open-access article distributed under the terms and conditions of the Creative Commons Attribution license (http://creativecommons.org/licenses/by/4.0/). 